\title{
Association between prediabetes and risk of cardiovascular disease and all cause mortality: systematic review and meta-analysis
}

\author{
Yuli Huang, ${ }^{1}$ Xiaoyan Cai, ${ }^{2}$ Weiyi Mai, ${ }^{3}$ Meijun Li, ${ }^{1,4}$ Yunzhao Hu${ }^{1}$
}

${ }^{1}$ Department of Cardiology, First People's Hospital of Shunde (Affiliated Hospital at Shunde, Southern Medical University)

Foshan, 528300, China

${ }^{2}$ Clinical Medicine Research Centre, First People's Hospital of Shunde (Affiliated Hospital at Shunde, Southern Medical University), Foshan, China ${ }^{3}$ Department of Cardiology, First Affiliated Hospital of Sun

Yat-sen University, Guangzhou, China

${ }^{4}$ Department of Cardiology, Graduate College, Guangdong medical university, Zhanjiang, China

Correspondence to: $\mathrm{Y} \mathrm{Hu}$ huyunzha04406@163.com Additional material is published online only. To view please visit the journal online.

Cite this as: BMJ 2016;355:i5953 http://dx.doi.org/10.1136/bmj.i5953

Accepted: 21 October 2016

\section{ABSTRACT}

OBJECTIVES

To evaluate associations between different definitions of prediabetes and the risk of cardiovascular disease and all cause mortality.

DESIGN

Meta-analysis of prospective cohort studies.

DATA SOURCES

Electronic databases (PubMed, Embase, and Google Scholar).

\section{SELECTION CRITERIA}

Prospective cohort studies from general populations were included for meta-analysis if they reported adjusted relative risks with $95 \%$ confidence intervals for associations between the risk of composite cardiovascular disease, coronary heart disease, stroke, all cause mortality, and prediabetes.

\section{REVIEW METHODS}

Two authors independently reviewed and selected eligible studies, based on predetermined selection criteria. Prediabetes was defined as impaired fasting glucose according to the criteria of the American Diabetes Association (IFG-ADA; fasting glucose 5.6-6.9 $\mathrm{mmol} / \mathrm{L}$ ), the WHO expert group (IFG-WHO; fasting glucose 6.1-6.9 mmol/L), impaired glucose tolerance ( 2 hour plasma glucose concentration 7.8-11.0 mmol/L during an oral glucose tolerance test), or raised haemoglobin $\mathrm{A}_{1 \mathrm{c}}\left(\mathrm{HbA}_{1 \mathrm{c}}\right)$ of $39-47 \mathrm{mmol} / \mathrm{mol}$ (5.7-6.4\%) according to ADA criteria or $42-47 \mathrm{mmol} / \mathrm{mol}$ (6.0$6.4 \%$ ) according to the National Institute for Health and Care Excellence (NICE) guideline. The relative risks of all cause mortality and cardiovascular events were calculated and reported with $95 \%$ confidence intervals.

\section{WHAT IS ALREADY KNOWN ON THIS TOPIC}

Prediabetes, including impaired fasting glucose, impaired glucose tolerance, and mildly raised haemoglobin $A_{1 c}$, is a common worldwide condition

The cut points for impaired fasting glucose and haemoglobin $A_{1 c}$ for defining prediabetes are inconsistent in different guidelines

Reports on the association between prediabetes and all cause mortality and cardiovascular events are inconsistent

\section{WHAT THIS STUDY ADDS}

Prediabetes defined as impaired glucose tolerance or impaired fasting glucose was associated with an increased risk of cardiovascular disease and all cause mortality The risk increased in people with a fasting glucose concentration as low as $5.55 \mathrm{mmol} / \mathrm{L}$ $\mathrm{HbA}_{1 \mathrm{c}} 39-47 \mathrm{mmol} / \mathrm{mol}$ or $42-47 \mathrm{mmol} / \mathrm{mol}$ was associated with an increased risk of composite cardiovascular disease and coronary heart disease

Lifestyle modification is the main management for people with prediabetes

\section{RESULTS}

53 prospective cohort studies with 1611339 individuals were included for analysis. The median follow-up duration was 9.5 years. Compared with normoglycaemia, prediabetes (impaired glucose tolerance or impaired fasting glucose according to IFG-ADA or IFG-WHO criteria) was associated with an increased risk of composite cardiovascular disease (relative risk 1.13, 1.26, and 1.30 for IFG-ADA, IFG-WHO, and impaired glucose tolerance, respectively), coronary heart disease $(1.10,1.18$, and 1.20 , respectively), stroke (1.06, 1.17 , and 1.20 , respectively), and all cause mortality $(1.13,1.13$ and 1.32 ,

respectively). Increases in $\mathrm{HBA}_{1 \mathrm{c}}$ to $39-47 \mathrm{mmol} / \mathrm{mol}$ or $42-47 \mathrm{mmol} / \mathrm{mol}$ were both associated with an increased risk of composite cardiovascular disease (1.21 and 1.25, respectively) and coronary heart disease (1.15 and 1.28, respectively), but not with an increased risk of stroke and all cause mortality.

\section{CONCLUSIONS}

Prediabetes, defined as impaired glucose tolerance, impaired fasting glucose, or raised $\mathrm{HbA}_{1 c}$, was associated with an increased risk of cardiovascular disease. The health risk might be increased in people with a fasting glucose concentration as low as 5.6 $\mathrm{mmol} \mathrm{L}$ or $\mathrm{HbA}_{1 \mathrm{c}}$ of $39 \mathrm{mmol} / \mathrm{mol}$.

\section{Introduction}

Prediabetes is defined as an intermediate metabolic state between normoglycaemia and diabetes and includes those with impaired glucose tolerance and impaired fasting glucose. ${ }^{1}$ Although impaired glucose tolerance is consistently defined as a 2 hour plasma glucose concentration of 7.8-11.0 mmol/L during an oral glucose tolerance test, the cut-off point for diagnosis of impaired fasting glucose remains controversial. The World Health Organization (WHO) defines impaired plasma glucose as fasting plasma glucose of 6.1-6.9 mmol/L, ${ }^{2}$ while the 2003 American Diabetes Association (ADA) guideline recommended a cut-off point of 5.6-6.9 mmol/L. ${ }^{3}$ The ADA's proposal for defining impaired fasting glucose is contentious and has not been adopted by other international guidelines for diabetes management. ${ }^{45}$ Some researchers opposed to the change believe that it greatly increases the prevalence of what is classified as impaired fasting glucose without any clear association with clinical complications, ${ }^{67}$ especially for cardiovascular disease and all cause mortality. Although some prospective studies have shown that the 2003 ADA category of impaired fasting glucose with the lower cut-off point is associated with an increased risk of 
cardiovascular disease, ${ }^{89}$ other studies have not found a similar association. ${ }^{10-12}$ Several previous meta-analyses have led to conflicting conclusions, ${ }^{13-15}$ which might be because of differences in endpoint assessments and inclusion criteria. Furthermore, the ADA also suggested haemoglobin $\mathrm{A}_{1 \mathrm{c}}\left(\mathrm{HbA}_{1 \mathrm{c}}\right)$ of 39-47 $\mathrm{mmol} / \mathrm{mol}$ (5.7-6.4\%) could be used as another marker to define prediabetes, while the National Institute for Health and Care Excellence (NICE) ${ }^{16}$ and the International Expert Committee ${ }^{17}$ suggested using a higher cut point of $42-47 \mathrm{mmol} / \mathrm{mol}(6.0-6.4 \%)$ for prediabetes. It is unclear whether the raised $\mathrm{HbA}_{1 \mathrm{c}}$ for defining prediabetes is useful for predicting future cardiovascular disease.

Considering these inconsistencies, we performed a meta-analysis of prospective cohort studies from general populations to evaluate associations between different definitions of prediabetes and the risk of composite cardiovascular events, coronary heart disease, stroke, and all cause mortality.

\section{Methods}

\section{Search strategy and selection criteria}

Following recommendations of the Meta-analysis of Observational Studies in Epidemiology group, ${ }^{18}$ we searched electronic databases (PubMed, Embase, and Google Scholar) for prospective cohort studies up to 31 July 2016 using a combined MeSH heading and text search strategy with the following terms: "blood glucose”, "hyperglycaemia”, "impaired fasting glucose”, "impaired glucose intolerance”, "prediabetes”, "prediabetic state”, "borderline diabetes", "higher risk of diabetes", "high risk of diabetes", "hemoglobin $\mathrm{A}_{1 \mathrm{c}}$ " or " $\mathrm{HbA}_{1 \mathrm{c}}$ " and "cardiovascular disease", "cardiovascular event”, "cardiocerebrovascular disease”, "cerebrovascular disease", "cerebrovascular disorder", "cerebrovascular attack", “stroke”, “cerebral infarction”, "coronary artery disease”, "coronary heart disease", "ischemic heart disease", "myocardial infarction", "mortality”, or "death" and "risk". We also manually checked reference lists to identify other potential studies and restricted the search to human studies. Appendix 1 shows the detailed methods used for searching all the databases.

Studies were included for analysis if they were prospective cohort studies with blood glucose and other cardiovascular risk factors measured at baseline; all participants were aged $\geq 18$; and they provided adjusted relative risks and 95\% confidence intervals for composite cardiovascular events (combination of coronary heart disease, stroke, or other type of cardiovascular disease together), coronary heart disease, stroke, and all cause mortality associated with prediabetes compared with normoglycaemia.

Prediabetes was defined as impaired fasting glucose according to WHO criteria (IFG-WHO: 6.1-6.9 mmol/L) ${ }^{2}$ or the ADA definition (IFG-ADA: $5.6-6.9 \mathrm{mmol} / \mathrm{L}$ ), ${ }^{3}$ impaired glucose tolerance (2 hour plasma glucose 7.8-11.0 mmol/L during an oral glucose tolerance test), ${ }^{2}$ or raised $\mathrm{HbA}_{1 \mathrm{c}}$ according to ADA criteria ( $\left.\mathrm{HbA}_{1 \mathrm{c}}-\mathrm{ADA}: 39-47 \mathrm{mmol} / \mathrm{mol}\right)^{3}$ or NICE ( $\mathrm{HbA}_{1 \mathrm{c}}$-NICE: $\left.42-47 \mathrm{mmol} / \mathrm{mol}\right){ }^{16}$
We excluded studies if enrolment was dependent on patients having a particular condition (such as a history of cardiovascular disease) or other cardiovascular risk factors (such as hypertension, chronic kidney disease) and risks for associated events were unadjusted. If multiple articles were derived from the same cohort and reported the same associated events, we included only the latest published data for our primary analysis.

As it has been reported that the potential pathological mechanisms and cardiovascular risk factors are different in those with impaired fasting glucose, impaired glucose tolerance, and raised $\mathrm{HbA}_{1 \mathrm{c}},{ }^{1920}$ we further excluded studies if they reported only data associated with combined impaired fasting glucose or impaired glucose tolerance or combined with either impaired fasting glucose or raised $\mathrm{HbA}_{1 \mathrm{c}}$, but not isolated impaired fasting glucose, impaired glucose tolerance, and $\mathrm{HbA}_{1 \mathrm{c}}$ categories. Because the rate of progression to diabetes is higher in people who have both impaired fasting glucose and impaired glucose tolerance, ${ }^{21}$ however, we included people with both as a separate category for analysis to explore whether they are at higher risk of cardiovascular disease than those with isolated impaired fasting glucose or isolated impaired glucose tolerance.

\section{Patient involvement}

Patients were not involved in setting the research question, in the outcome measures, in the design, or in the implementation of the study. No patients were asked to advice on interpretation or writing up of results. There are no plans to disseminate the results of the research to study participants or the relevant patient community.

\section{Data extraction and quality assessment}

Two reviewers (YulH and XC) independently screened the titles and abstracts of the reports, and full copies of potentially suitable studies were obtained. Study information such as ethnicity, participant number, age, sex, follow-up duration, adjusted risk factors, and events assessment was recorded on pretested standard forms.

We used Newcastle-Ottawa quality assessment scale for quality assessment of cohort studies, ${ }^{22}$ in which a study is judged based on selection (four items, one star each), comparability (one item, up to two stars), and exposure/outcome (three items, one star each). In this meta-analysis we graded quality as good ( $\geq 7$ stars), fair (4-6 stars), and poor (<4 stars). ${ }^{2324}$ We also evaluated whether the studies had adequately adjusted for potential confounders (at least five of six confounders including sex, age, hypertension or blood pressure or antihypertensive treatment, body mass index (BMI) or other measure of overweight/obesity, cholesterol, and smoking).

\section{Statistical analysis}

Primary outcomes were relative risks for composite cardiovascular events and all cause mortality. Secondary outcomes were relative risks for coronary heart disease and stroke in individuals by using different definitions of prediabetes compared with normoglycaemia. 
Subgroup analyses of primary outcomes were conducted according to sex (men $v$ women), ethnicity (Asian $v$ non-Asian), age (average $<55 v \geq 55$ ), possibility of enrolling patients with diabetes (yes $v$ no), duration of follow-up ( $<10 v \geq 10$ years), exclusion of individuals with baseline cardiovascular disease (yes $v$ no), and study quality (adequate adjustment $v$ inadequate adjustment). For composite cardiovascular events, we also performed subgroup analysis according to endpoint (incidence $v$ mortality). We used $\chi^{2}$ to test for subgroup differences-that is, whether the observed differences in the subgroups are compatible with chance alone. A low $\mathrm{P}$ value (or a large $\chi^{2}$ statistic relative to its degree of freedom) provides evidence of heterogeneity beyond chance..$^{25}$

For meta-analysis we used data on the adjusted outcome in every included study. We logarithmically transformed these data and calculated corresponding standard errors. An inverse variance approach was used to combine the log relative risk and SE. In cases where the odds ratio was described, we converted data to a relative risk for meta-analysis ( $R R=O R /([1-$ $p R e f]+[p R e f \times O R])$, where $p R e f$ is the prevalence of the outcome in the reference group. ${ }^{26}$

Heterogeneity among studies was assessed with the $Q$ statistic. $P_{Q \text { statistic }} \geq 0.10$ was considered to indicate no significant heterogeneity among the included studies. Even when a lack of heterogeneity was indicated, however, we report the results from the DerSimonian and Laird random effects models over the fixed effects model because the included studies differed to some extent, both clinically and methodologically (for example, baseline characteristics of the participants, follow-up duration, and adjustment of confounders). If no heterogeneity exits in the pooled data, results of random and fixed effects models are the same, and if signif-

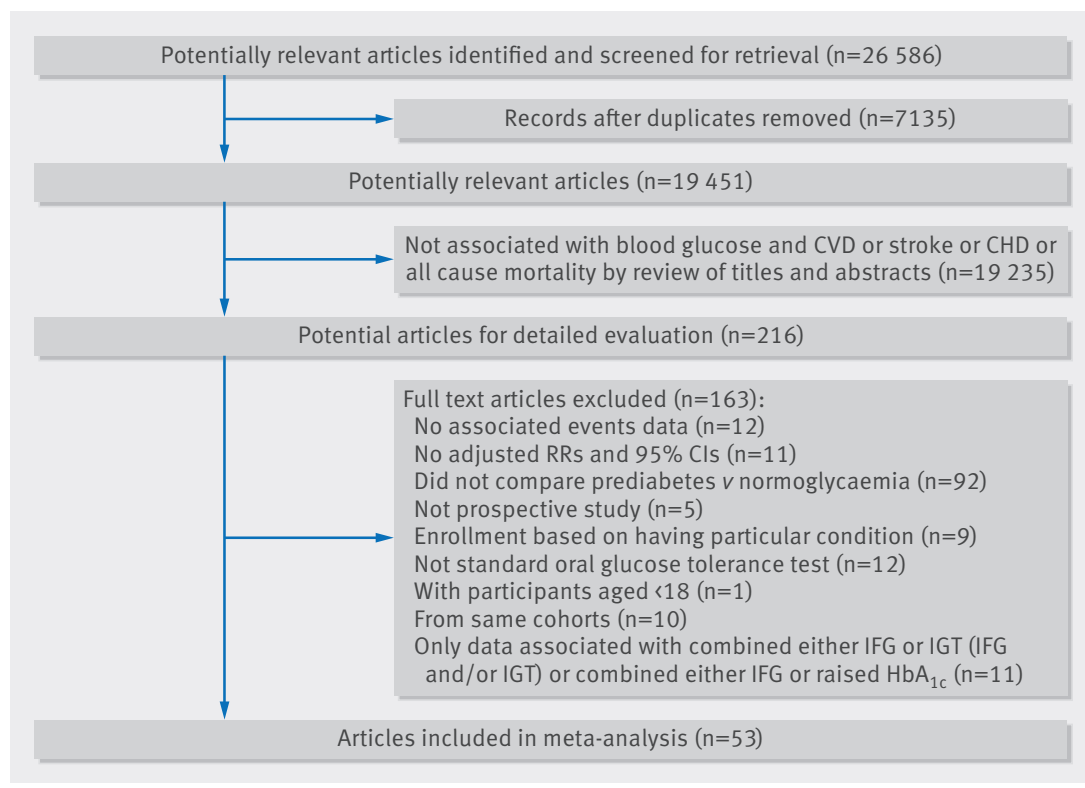

Fig 1 | Flow of papers through review of prediabetes and risk of cardiovascular disease and all cause mortality. $\mathrm{CVD}=$ cardiovascular disease, $\mathrm{CHD}=$ coronary heart disease, IFG=impaired fasting glucose, IGT= impaired glucose tolerance icant heterogeneity is present, a random effects model is more conservative. ${ }^{27}$ To further confirm the results, we have presented the results with both fixed/random effects models in the forest plots.

We evaluated publication bias by inspecting funnel plots for each outcome in which the natural log relative risk was plotted against the SE and further tested with Egger's and Begg's tests. To assess the effect of individual studies on the estimated relative risk, we conducted a sensitivity analysis in which we recalculated the pooled relative risk by omitting one study at a time. Analyses were performed with RevMan 5.3 (Cochrane Collaboration, Copenhagen, Denmark) and Stata 12.0 (StataCorp LP, College Station, TX).

\section{Results}

\section{Studies retrieved and characteristics}

Our initial search returned 26568 articles. After we screened titles and abstracts, 216 articles qualified for a full review (fig 1). We finally included 53 prospective cohort studies, ${ }^{8-1228-75}$ comprising 1611339 individuals for analysis. For the association between prediabetes and risk of all cause mortality, composite cardiovascular disease, coronary heart disease, and stroke, 25, 35, 24, and 18 studies, respectively, provided data.

Table A in appendix 2 provides the key characteristics of the included studies. All were derived from the general population. Nine studies enrolled only men, and all others included both men and women. The duration of follow-up ranged from two to 20 years, with a median duration of 9.5 years. According to quality assessment criteria, 45 studies were graded as good quality and eight as fair (table B in appendix 2). Furthermore, based on adjusted confounders, 33 studies met our criteria for adequate adjustment, while 20 studies did not adequately adjust for potential confounders (table $\mathrm{C}$ in appendix 2).

All studies excluded people with fasting plasma glucose concentration $\geq 7.0 \mathrm{mmol} / \mathrm{L}$, except for one that only measured 2 hour plasma glucose concentration during an oral glucose tolerance test at baseline, ${ }^{28}$ with the possibility that a few patients with fasting plasma glucose $\geq 7.0 \mathrm{mmol} / \mathrm{L}$ were enrolled in the impaired glucose tolerance groups. Twenty eight studies measured fasting plasma glucose only at baseline without an oral glucose tolerance test; these studies therefore possibly enrolled patients with 2 hour plasma glucose $\geq 11.1 \mathrm{mmol} / \mathrm{L}$.

\section{Prediabetes and all cause mortality}

Twenty five studies reported data for the association between prediabetes and risk of all cause mortality. Random effects models analyses show that prediabetes was associated with an increased risk of all cause mortality: IFG-ADA (relative risk 1.13, 95\% confidence interval 1.02 to 1.25$)$, IFG-WHO (1.13, 1.05 to 1.21 ), impaired glucose tolerance $(1.32,1.23$ to 1.40$)$. Prediabetes was not associated with an increased risk of all cause mortality when it was defined as $\mathrm{HbA}_{1 \mathrm{c}} 39-47$ $\mathrm{mmol} / \mathrm{mol}$ (0.97, 0.88 to 1.07$)$ or $\mathrm{HbA}_{1 \mathrm{c}} 42-47 \mathrm{mmol} / \mathrm{mol}$ (1.21, 0.95 to 1.56 ) (fig 2). Data from a single 


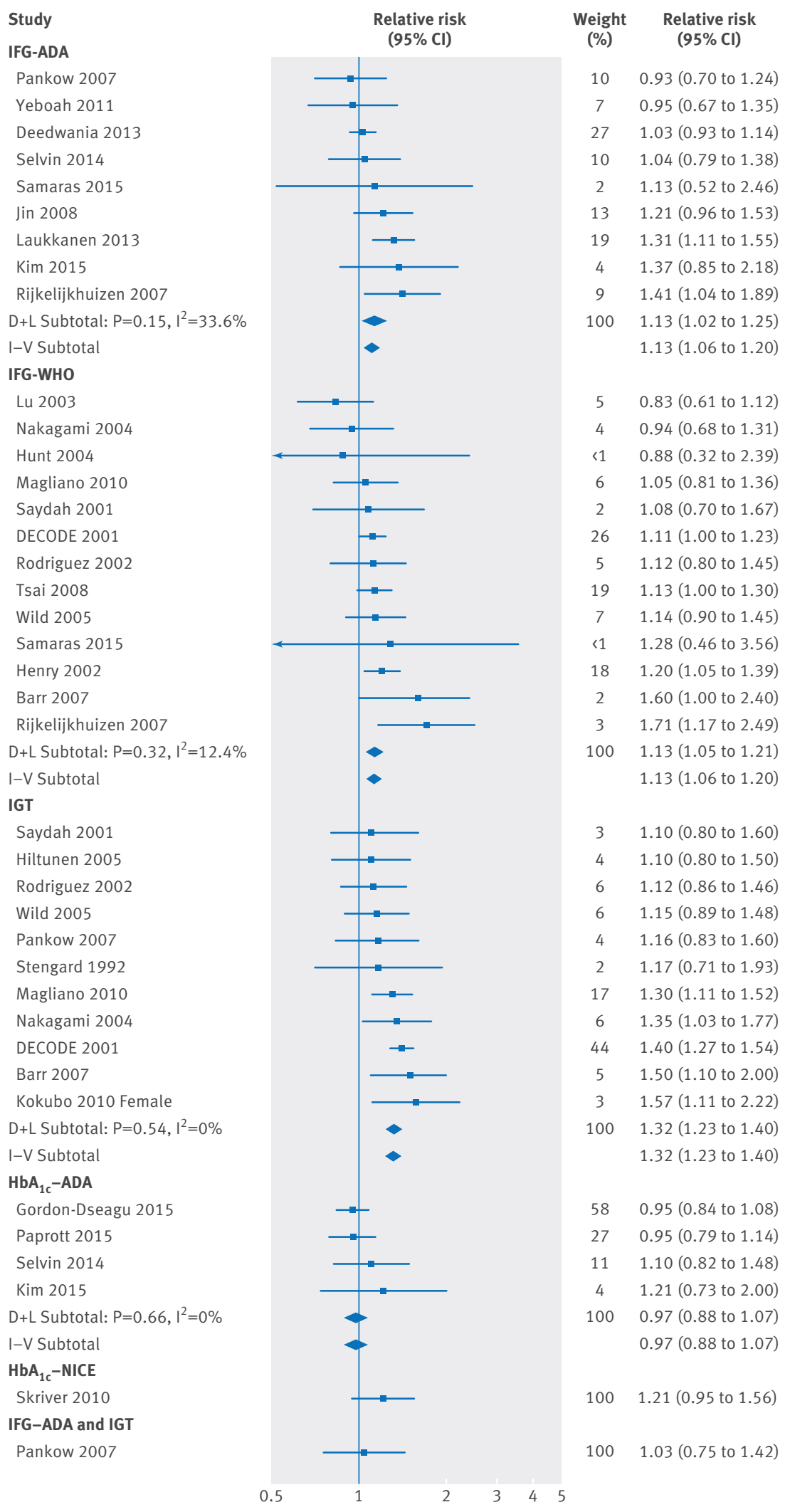

Fig $2 \mid$ Association between prediabetes and risk of all cause mortality. $\mathrm{D}+\mathrm{L}=$ DerSimonian and Laird random effects models; $\mathrm{HbA}_{1 c}-\mathrm{ADA}=$ prediabetes defined as raised $\mathrm{HbA}_{1 c}$ according to American Diabetes Association (ADA) criteria (39-47 mmol/mol); $\mathrm{HbA}_{1 \mathrm{c}^{-}}$ NICE=prediabetes defined as raised $\mathrm{HbA}_{1 \mathrm{c}}$ according to $\mathrm{NICE}$ guidance $(42-47 \mathrm{mmol} / \mathrm{mol})$; IFG-ADA=impaired fasting glucose (IFG) according to ADA criteria (fasting plasma glucose of 5.6-6.9 mmol/L); IFG-WHO=IFG according to WHO criteria (6.1-6.9 mmol/L); IGT=impaired glucose tolerance; I-V=inverse variance fixed effects models study showed that prediabetes defined as IFG-ADA and impaired glucose tolerance was not associated with increased risk of all caused mortality (1.03, 0.75 to 1.42). ${ }^{48}$ No studies reported the risk of all cause mortality in patients with both IFG-WHO and impaired glucose tolerance. The increased risk of all cause mortality was significantly higher in the impaired glucose tolerance group than in groups according to other definitions of prediabetes $(\mathrm{P}<0.001)$.

\section{Prediabetes and composite cardiovascular events}

Thirty five studies reported data for the association between prediabetes and risk of composite cardiovascular disease. Table D in appendix 2 provides detailed definitions of composite cardiovascular disease in every included study. Random effects models analyses showed that prediabetes was associated with increased composite cardiovascular events when it was defined as IFG-ADA (relative risk 1.13, 95\% confidence interval 1.05 to 1.21$)$, IFG-WHO (1.26, 1.12 to 1.41$)$, impaired glucose tolerance (1.30, 1.19 to 1.42 ), $\mathrm{HbA}_{1 \mathrm{c}} 38.8-46.4 \mathrm{mmol} / \mathrm{mol}$ (1.21, 1.01 to 1.44$)$, or $\mathrm{HbA}_{1 \mathrm{c}} 42.11-46.4 \mathrm{mmol} / \mathrm{mol}$ (1.25, 1.01 to 1.55 ) (fig 3 ). The difference in risk of cardiovascular disease with different definitions of prediabetes was not significant $(\mathrm{P}=0.16)$. No studies reported the risk of composite cardiovascular events in patients with both impaired plasma glucose (either IFG-ADA or IFG-WHO) and impaired glucose tolerance.

\section{Prediabetes and risk of coronary heart disease}

Twenty four studies reported data for the association between prediabetes and risk of coronary heart disease. Similar to results for composite cardiovascular events, prediabetes was associated with increased risk of coronary heart disease when it was defined as IFG-ADA (relative risk 1.10, 95\% confidence interval 1.04 to 1.16), IFG-WHO (1.18, 1.08 to 1.28$)$, impaired glucose tolerance (1.20, 1.0 to 1.44$), \mathrm{HbA}_{1 \mathrm{c}} 39-47 \mathrm{mmol} / \mathrm{mol}(1.15,1.01$ to 1.33), or $\mathrm{HbA}_{1 \mathrm{c}} 42-47 \mathrm{mmol} / \mathrm{mol}$ (1.28, 1.03 to 1.59) (fig 4). Combined data from two studies, however, did not show an increased risk of coronary heart disease in people with both IFG-ADA and impaired glucose tolerance (0.93, 0.70 to 1.25$)$. No studies reported the risk of coronary heart disease in people with both IFG-WHO and impaired glucose tolerance. There was no significant different in risk of coronary heart disease with different definition of prediabetes $(\mathrm{P}=0.36)$.

\section{Prediabetes and risk of stroke}

Eighteen studies reported data for the association between prediabetes and risk of stroke. Combined data showed that IFG-ADA (relative risk 1.06, 95\% confidence interval 1.01 to 1.11$)$, IFG-WHO $(1.17,1.09$ to 1.25$)$, or impaired glucose tolerance (1.20, 1.0 to 1.45$)$ were associated with an increased risk of stroke after multivariate adjustment. The risk of stroke, however, was not significant in studies that defined prediabetes as raised $\mathrm{HbA}_{1 \mathrm{c}}$, either according to the ADA (1.05, 0.81 to 1.35) or NICE recommendation (1.33, 0.89 to 1.99) (fig 5). No studies reported data the risk of stroke with prediabetes defined as combined impaired fasting glucose (either 
Fig 3 | Association between prediabetes and composite cardiovascular events.

$\mathrm{D}+\mathrm{L}=$ DerSimonian and Laird random effects models; $\mathrm{HbA}_{1 \mathrm{c}}$ -

$A D A=$ prediabetes defined as raised $\mathrm{HbA}_{1 \mathrm{c}}$ according to American Diabetes Association (ADA) criteria (39-47 mmol $/ \mathrm{mol}$ ); $\mathrm{HbA}_{1 \mathrm{c}}$-NICE=prediabetes defined as raised $\mathrm{HbA}_{1 c}$ according to NICE guidance (42-47 mmol/ $\mathrm{mol})$; IFG-ADA=impaired fasting glucose (IFG) according to ADA criteria (fasting plasma glucose of 5.6-6.9 mmol/L); IFG-WHO=IFG according to WHO criteria (6.1-6.9 $\mathrm{mmol} / \mathrm{L}$ ); IGT=impaired glucose tolerance; $\mathrm{I}-\mathrm{V}=$-inverse variance fixed effects models
Study

IFG-ADA

Khang 2010

Deedwania 2013

Kim 2013

Ma 2012

Kim 2015

Schottker 2013

Yeboah 2011

Selvin 2014

Levitzky 2008

Kokubo 2010

Wang 2007a

Liu 2007

Rijkelijkhuizen 2007

Laukkanen 2013

Jin 2008

$D+L$ Subtotal: $P=0.009,\left.\right|^{2}=52.7 \%$ I-V Subtotal

IFG-WHO

Saydah 2001

Lu 2003

Rodriguez 2002

Oizumi 2008

Nakagami 2004

Magliano 2010

Wild 2005

DECODE 2001

Nakanishi 2004

Wang 2007a

Barzilay 1999

Nilsson 2007

Tsai 2008

Henry 2002

Hunt 2004

Chien 2008

Rijkelijkhuizen 2007

Barr 2007

$D+L$ Subtotal: $P=0.06, I^{2}=36.6 \%$

I-V Subtotal

IGT

Saydah 2001

Rodriguez 2002

Stengard 1992

Wild 2005

Barr 2007

Chien 2008

Barzilay 1999

Magliano 2010

Nakagami 2004

DECODE 2001

Oizumi 2008

Wang 2007a

Tai 2004

$D+L$ Subtotal: $P=0.82,\left.\right|^{2}=0 \%$

I-V Subtotal

$\mathrm{HbA}_{1 \mathrm{c}}-\mathrm{ADA}$

Schottker 2013

Gordon-Dseagu 2015

Kim 2015

Eastwood 2015

Selvin 2014

D+L Subtotal: $P<0.001, I^{2}=82.7 \%$

I-V Subtotal

$\mathrm{HbA}_{1 \mathrm{c}}-\mathrm{NICE}$

Eastwood 2015

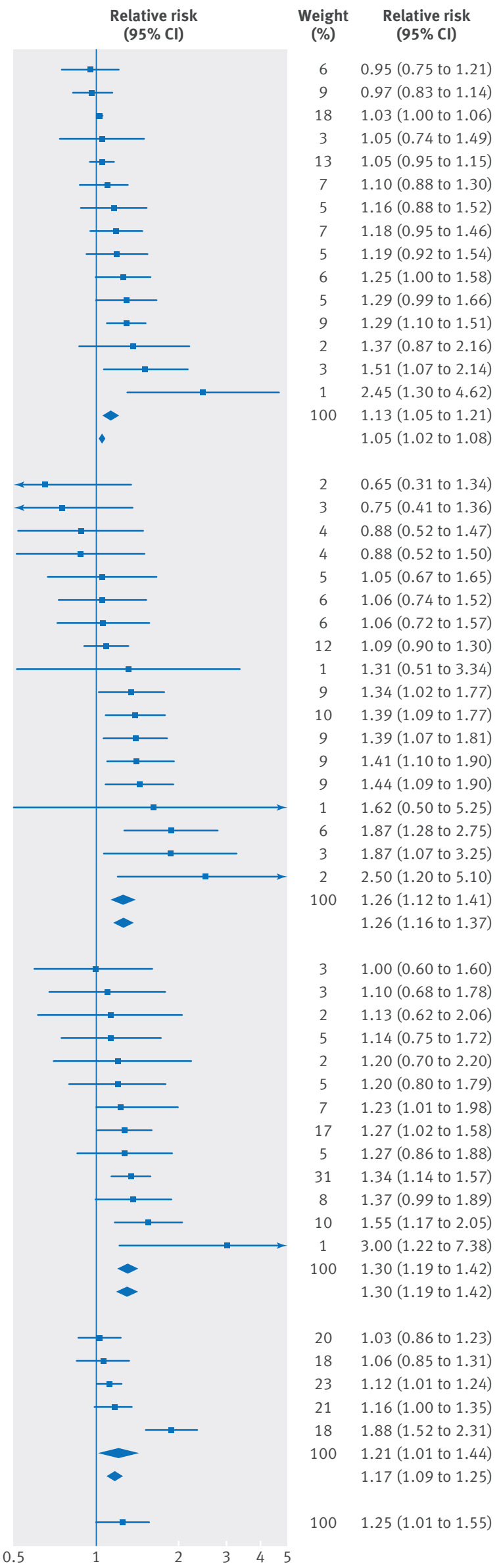




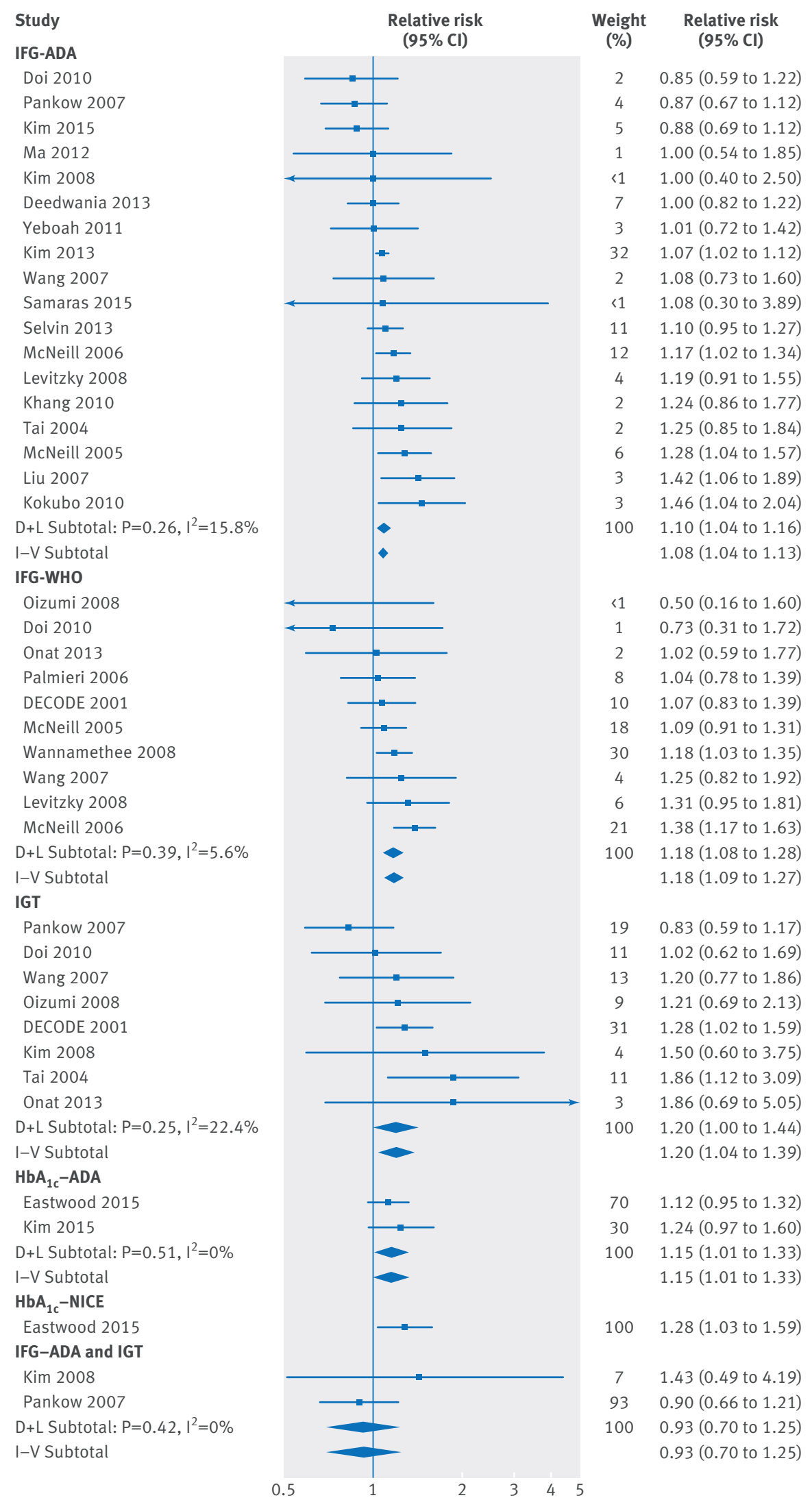

Fig $4 \mid$ Association between prediabetes and risk of coronary heart disease. $D+L=D e r S i m o n i a n$ and Laird random effects models; $\mathrm{HbA}_{1 \mathrm{c}}-\mathrm{ADA}=$ prediabetes defined as raised $\mathrm{HbA}_{1 \mathrm{c}}$ according to American Diabetes Association (ADA) criteria (39-47 mmol$/ \mathrm{mol}) ; \mathrm{HbA}_{1 c}-\mathrm{NICE}=$ prediabetes defined as raised $\mathrm{HbA}_{1 \mathrm{c}}$ according to NICE guidance (42-47 mmol$\left./ \mathrm{mol}\right)$; IFG-ADA=impaired fasting glucose (IFG) according to ADA criteria (fasting plasma glucose of 5.6-6.9 mmol/L); IFG-WHO=IFG according to WHO criteria (6.1-6.9 $\mathrm{mmol} / \mathrm{L})$; IGT=impaired glucose tolerance; I-V=inverse variance fixed effects models 
IFG-ADA or IFG-WHO) and impaired glucose tolerance. There was no significant different for increased risk of stroke in different definition of prediabetes $(\mathrm{P}=0.64)$.

\section{Sensitivity analyses and subgroup analyses}

We found no evidence of publication bias based on visual inspection of funnel plots (appendix 3) or according to Begg's or Egger's tests (all $\mathrm{P}>0.1$ ). Sensitivity analyses confirmed that the association between endpoint events and the different definitions of prediabetes did not change with the use of random effects models or fixed effects models for the meta-analysis. Furthermore, considering smoking is the strongest confounder for cardiovascular disease, we further performed a sensitivity analysis on primary outcomes with data with adjustment for smoking. We found that after controlling for smoking, the presence of prediabetes remained

\begin{tabular}{|c|c|c|c|}
\hline $\begin{array}{l}\text { Study } \\
\text { IFG-ADA }\end{array}$ & $\begin{array}{l}\text { Relative risk } \\
\qquad(95 \% \mathrm{Cl})\end{array}$ & $\begin{array}{l}\text { Weight } \\
\text { (\%) }\end{array}$ & $\begin{array}{l}\text { Relative risk } \\
\quad(95 \% \mathrm{Cl})\end{array}$ \\
\hline Doi 2010 & & 1 & $0.83(0.53$ to 1.30$)$ \\
\hline Yeboah 2011 & & 1 & 0.85 (0.48 to 1.51$)$ \\
\hline Deedwania 2013 & & 7 & $0.86(0.72$ to 1.03$)$ \\
\hline Khang 2010 & - & 2 & $0.86(0.63$ to 1.16$)$ \\
\hline Kim 2015 & - & 3 & $1.05(0.80$ to 1.37$)$ \\
\hline Kim 2013 & - & 37 & 1.07 (1.01 to 1.13$)$ \\
\hline Ma 2012 & - & 1 & 1.09 (0.71 to 1.69$)$ \\
\hline Sung 2009 & - & 45 & $1.10(1.05$ to 1.15$)$ \\
\hline Kokubo 2010 & - & 2 & 1.11 (0.81 to 1.52$)$ \\
\hline Liu 2007 & & 1 & $1.14(0.73$ to 1.78$)$ \\
\hline Samaras 2015 & 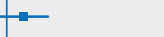 & $<1$ & $1.46(0.60$ to 3.55$)$ \\
\hline$D+L$ Subtotal: $P=0.32, I^{2}=13.4 \%$ & $\bullet$ & 100 & $1.06(1.01$ to 1.11$)$ \\
\hline I-V Subtotal & $\bullet$ & & 1.07 (1.04 to 1.11$)$ \\
\hline \multicolumn{4}{|l|}{ IFG-WHO } \\
\hline Doi 2010 & & $\ll 1$ & $0.98(0.22$ to 4.37$)$ \\
\hline Oizumi 2008 & & 1 & 1.11 (0.61 to 2.02$)$ \\
\hline Sung 2009 & $\rightarrow$ & 70 & $1.15(1.06$ to 1.25$)$ \\
\hline Hyvarinen 2009 & $\longrightarrow$ & 17 & $1.20(0.96$ to 1.51$)$ \\
\hline Sui 2011 & $\longrightarrow$ & 9 & $1.18(1.00$ to 1.40$)$ \\
\hline Mazza 2001 & $\longrightarrow$ & 2 & 1.83 (1.10 to 3.00$)$ \\
\hline$D+L$ Subtotal: $P=0.64, I^{2}=0 \%$ & $\bullet$ & 100 & 1.17 (1.09 to 1.25$)$ \\
\hline I-V Subtotal & $\bullet$ & & $1.17(1.09$ to 1.25$)$ \\
\hline \multicolumn{4}{|l|}{ IGT } \\
\hline Doi 2010 & & 13 & $0.89(0.55$ to 1.44$)$ \\
\hline Hyvarinen 2009 & $\rightarrow-$ & 55 & $1.14(0.96$ to 1.35$)$ \\
\hline Kaarisalo 2006 & & 13 & $1.48(0.91$ to 2.41$)$ \\
\hline Oizumi 2008 & & 19 & $1.51(1.02$ to 2.24$)$ \\
\hline$D+L$ Subtotal: $P=0.28, I^{2}=21.4 \%$ & $\longrightarrow$ & 100 & $1.20(1.00$ to 1.45$)$ \\
\hline I-V Subtotal & $<$ & & $1.18(1.03$ to 1.36$)$ \\
\hline \multicolumn{4}{|l|}{$\mathrm{HbA}_{1 \mathrm{c}}-\mathrm{ADA}$} \\
\hline Kim 2015 & - & 75 & $1.00(0.74$ to 1.33$)$ \\
\hline Eastwood 2015 & $\longrightarrow$ & 25 & 1.21 (0.73 to 2.01$)$ \\
\hline$D+L$ Subtotal: $P=0.52,\left.\right|^{2}=0 \%$ & & 100 & $1.05(0.81$ to 1.35$)$ \\
\hline I-V Subtotal & & & $1.05(0.81$ to 1.35$)$ \\
\hline \multicolumn{4}{|l|}{$\mathrm{HbA}_{1 \mathrm{c}}-\mathrm{NICE}$} \\
\hline Eastwood 2015 & & 100 & $1.33(0.89$ to 1.99$)$ \\
\hline & 2 & & \\
\hline
\end{tabular}

Fig $5 \mid$ Association between prediabetes and risk of stroke. $\mathrm{D}+\mathrm{L}=$ DerSimonian and Laird random effects models; $\mathrm{HbA}_{1 c}-\mathrm{ADA}=$ prediabetes defined as raised $\mathrm{HbA}_{1 \mathrm{c}}$ according to American Diabetes Association (ADA) criteria (39-47 mmol/mol); $\mathrm{HbA}_{1 c}-\mathrm{NICE}=$ prediabetes defined as raised $\mathrm{HbA}_{1 \mathrm{c}}$ according to NICE guidance ( $\left.42-47 \mathrm{mmol} / \mathrm{mol}\right)$; IFG-ADA=impaired fasting glucose (IFG) according to ADA criteria (fasting plasma glucose of 5.6-6.9 mmol/L); IFG-WHO=IFG according to WHO criteria (6.1-6.9 $\mathrm{mmol} / \mathrm{L})$; IGT=impaired glucose tolerance; $\mathrm{I}-\mathrm{V}=$ =inverse variance fixed effects models associated with an increased risk of composite cardiovascular disease when it was defined as IFG-ADA, IFGWHO, impaired glucose tolerance, or $\mathrm{HbA}_{1 \mathrm{c}}$ 39-47 $\mathrm{mmol} / \mathrm{mol}$ or $42-47 \mathrm{mmol} / \mathrm{mol}$ (fig A in appendix 4). The risk of all cause mortality associated with IFG-ADA was not significant under random effects models analysis (relative risk 1.09, 95\% confidence interval 0.97 to 1.22), though it did reach significance when we used fixed effects models (1.08, 1.0 to 1.17). Furthermore, IFG-WHO or impaired glucose tolerance was still associated with an increased risk of all cause mortality after we excluded data from studies that did not adjust for smoking (fig B in appendix 4).

Tables E and F in appendix 2 show the results of subgroup analyses for the risk of all cause mortality and composite cardiovascular events associated with prediabetes defined as IFG-ADA, IFG-WHO, or impaired glucose tolerance. Briefly, we found no significant heterogeneity among all subgroup comparisons for prediabetes defined as IFG-WHO or impaired glucose tolerance (all $\mathrm{P} \geq 0.05$ ). IFG-ADA, however, was significantly associated with all cause mortality in participants with a mean age $<55$ at study entry, but not in those aged $\geq 55$ ( $P=0.009$ for interaction). This was the only significant heterogeneity we observed among all subgroup comparisons in our study. We did not perform subgroup analyses for participants with other definitions of prediabetes because of the limited number of studies.

\section{Discussion}

\section{Principal findings}

In this meta-analysis with a large sample size (comprising 1611339 individuals), we found that prediabetes defined as impaired fasting glucose or impaired glucose tolerance was associated with an increased risk of composite cardiovascular events, coronary heart disease, stroke, and all cause mortality. Importantly, we observed increased risks when fasting plasma glucose was as low as $5.6 \mathrm{mmol} / \mathrm{L}$ according to the current ADA definition of impaired fasting glucose (IFG-ADA). ${ }^{3}$ We also found that the risks for composite cardiovascular events and coronary heart disease were higher in people with prediabetes defined as raised $\mathrm{HbA}_{1 \mathrm{c}}$ of $39-47$ $\mathrm{mmol} / \mathrm{mol}$ (according to ADA criteria) ${ }^{3}$ or $42-47 \mathrm{mmol} /$ mol (according to NICE), ${ }^{16}$ respectively.

\section{Strengths and limitations of study}

An important strength of our study is the large sample size. We included only prospective cohort studies with adjusted relative risks from general populations. There were, however, some limitations. Firstly, though individuals with prediabetes are more likely to progress to diabetes than those with normoglycaemia, most of the included studies did not adjust for the future development of diabetes during the follow-up period. Therefore, it is still unclear whether the long term health risk associated with prediabetes is because of a mild increase of blood glucose concentration or because of future progression to diabetes. Nevertheless, the results indicate that, on the basis of a "snapshot" measurement 
of blood glucose, prediabetes is associated with an increased risk of cardiovascular disease as well as all cause mortality, and early lifestyle interventions should be implemented in these populations. Secondly, almost half of the included studies measured fasting plasma glucose only at baseline, without performing an oral glucose tolerance test; therefore, these studies possibly enrolled patients with increased 2 hour plasma glucose. The risk of cardiovascular events and all cause mortality associated with impaired fasting glucose could be confounded by the undetected increase in 2 hour plasma glucose (diabetes defined by 2 hour plasma glucose). We found no significant heterogeneity, however, in subgroup comparisons conducted according to the possibility of enrolling patients with diabetes. Thirdly, we found that the risk of composite cardiovascular events and coronary heart disease was higher in people with mild raised $\mathrm{HbA}_{1 \mathrm{c}}$ (39-47 mmol/mol or $42-47 \mathrm{mmol} /$ mol), though the risk of stroke did not reach significance. These inconsistent results should be interpreted with caution because of the small numbers of studies included in these analyses. More prospective cohort studies that evaluate the level of $\mathrm{HbA}_{1 \mathrm{c}}$ and health risk are needed. Fourthly, there were too few studies to draw a solid conclusions for the risk of cardiovascular disease in people with both impaired fasting glucose and impaired glucose tolerance.

\section{Comparison with other studies}

Several previous meta-analyses have returned inconsistent results on the different definitions of prediabetes and target organ damage. In 2014, our group reported that prediabetes, defined as IFG-WHO, impaired glucose tolerance, but not IFG-ADA, was associated with increased risk of all cause and cardiovascular mortality. ${ }^{76}$ Similarly, another published meta-analysis that included 15 prospective cohort studies (including 760925 participants) reported that the risk of stroke increased in people with IFG-WHO or impaired glucose tolerance but not in people with IFG-ADA. ${ }^{14}$ In the past few years, however, an increasing number of studies have reported on the association between health risks and IFG-ADA. We updated our data and found differences with our previous analysis, with the risks for all cause mortality, composite cardiovascular disease, coronary heart disease, and stroke all significantly increased in people with IFG-ADA.

Ford and colleagues included 18 studies with 175152 participants in their analysis and found that impaired fasting glucose (defined with either ADA or WHO criteria) and impaired glucose tolerance was associated with a modest increased risk of cardiovascular disease. ${ }^{15}$ Endpoint events in the studies included in that meta-analysis, however, were significantly different. For example, some had data only for coronary heart disease, ${ }^{37445}$ while others reported the risk of composite cardiovascular disease. ${ }^{83577}$ It is suggested that combining data with different events in a meta-analysis could produce misleading results. Contrary to the analysis conducted by Ford and colleagues, ${ }^{15}$ the large sample size in our study (53 prospective cohort studies comprising 1611339 participants) allowed us to analyse the risk of composite cardiovascular disease, coronary heart disease, and stroke separately. The strict inclusion criteria in our study were important to avoid heterogeneity among studies and lead to a reliable conclusion. Furthermore, Ford and colleagues did not analyse the risk of cardiovascular disease with prediabetes defined with $\mathrm{HbA}_{1 \mathrm{c}}$ criteria. ${ }^{15}$

\section{Future research}

Our findings strongly support the lower cut-off point for impaired fasting glucose proposed by the 2003 ADA guideline, and they have important public health implications. According to the 2003 ADA definition, the prevalence of prediabetes in adults was up to $36.2 \%$ in the $\mathrm{US}^{78}$ and $50.1 \%$ in China. ${ }^{79}$ Considering the high prevalence of prediabetes, successful intervention in these large populations could have major impacts on public health. The ADA suggests that lifestyle intervention is the fundamental management approach for prediabetes. ${ }^{80}$ For people with impaired glucose tolerance, lifestyle interventions can reduce the risk of progression to diabetes. ${ }^{81}$ Recently, Yates and colleagues reported that in patients with impaired glucose tolerance, a change in daily ambulatory activity can significantly decrease the risk of cardiovascular events. ${ }^{82}$ Similarly, the Da Qing diabetes prevention study also reported that lifestyle intervention in people with impaired glucose tolerance can reduce the incidence of cardiovascular and all cause mortality. ${ }^{83}$ It should be noted, however, that all these studies were performed on people with impaired glucose tolerance. There are few data in terms of interventions for prediabetes defined by impaired fasting glucose and $\mathrm{HbA}_{1 \mathrm{c}}$. Considering the different underlying pathophysiological mechanisms ${ }^{8485}$ and associated cardiovascular risk factors ${ }^{19} 20$ between impaired fasting glucose, impaired glucose tolerance, and raised $\mathrm{HbA}_{1 \mathrm{c}}$, future studies are urgently needed to explore effective interventions to decrease the risk of cardiovascular disease in people with prediabetes defined as impaired fasting glucose and raised $\mathrm{HbA}_{1 \mathrm{c}}$. Furthermore, it should be noted that prediabetes is not a disease but rather a risk factor for future diabetes and cardiovascular disease, and the findings in our study do not mean that pharmacological treatment is warranted in everyone with prediabetes. Further studies are needed to determine which phenotype of prediabetes can be benefit from pharmacological treatment. Nowadays, the ADA recommended pharmacological intervention can be considered in individuals with both impaired glucose tolerance and impaired fasting glucose and at least one of age $<60$, BMI $\geq 35$, family history of diabetes mellitus in first degree relative, high concentrations of triglycerides, reduced concentration of high density lipoprotein cholesterol, hypertension, and $\mathrm{HbA}_{1 \mathrm{c}}>42 \mathrm{mmol} /$ mol. ${ }^{80}$ Furthermore, pharmacological treatment should be individualised on the basis of the known efficacy and safety of drugs and accompanied by lifestyle intervention programmes. ${ }^{85}$ 
Interestingly, we found that the risk of all cause mortality was significantly higher in the impaired glucose tolerance group than in groups with other definition of prediabetes. There were, however, no significant differences in risks of cardiovascular disease, coronary heart disease, and stroke with different definitions of prediabetes. These results suggest that impaired glucose tolerance is a stronger risk factor for all cause mortality, but not for cardiovascular disease, than other definitions of prediabetes, which might be caused by the significant association between impaired glucose tolerance and non-cardiovascular death, especially cancer mortality. ${ }^{76}$ It has been reported that the risk of cancer mortality is greater with impaired glucose tolerance than with impaired fasting glucose. ${ }^{4686}$

\section{Conclusions and implications}

In conclusion, we found that prediabetes defined as impaired fasting glucose or impaired glucose tolerance is associated with an increased risk of composite cardiovascular events, coronary heart disease, stroke, and all cause mortality. There was an increased risk in people with fasting plasma glucose as low as $5.6 \mathrm{mmol} / \mathrm{L}$. Additionally, the risk of composite cardiovascular events and coronary heart disease increased in people with raised $\mathrm{HbA}_{1 \mathrm{c}}$. These results support the lower cutoff point for impaired fasting glucose according to ADA criteria as well as the incorporation of $\mathrm{HbA}_{1 \mathrm{c}}$ in defining prediabetes. At present, lifestyle modification is the mainstay management for people with prediabetes. High risk subpopulations with prediabetes, especially combined with other cardiovascular risk factors, should be selected for controlled trials of pharmacological treatment

We thank Jun Lu (Clinical Research Centre, the First Affiliated Hospital of Xi'an Jiaotong University, China) for help in statistical analysis.

Contributors: $\mathrm{YH}$ and $\mathrm{YunH}$ were responsible for the initial plan, study design, conducting the study, data interpretation. YH, XC, and WM were responsible for data collection, data extraction, statistical analysis, and manuscript drafting. $\mathrm{YH}, \mathrm{XC}$, and $\mathrm{ML}$ analysed and interpreted the data and critically revised the paper. $\mathrm{YH}$ and $\mathrm{YunH}$ are guarantors and had full access to all of the data, including statistical reports and tables), and take full responsibility for the integrity of the data and the accuracy of the data analysis.

Funding: This study was funded by the National Natural Science Foundation of China (No 81600239).

Competing interests: All author shave completed the ICMJE uniform disclosure form at www.icmje.org/coi_disclosure.pdf (available on request from the corresponding author) and declare: no support from any organisation for the submitted work; no financial relationships with any organizations that might have an interest in the submitted work in the previous three years; no other relationships or activities that could appear to have influenced the submitted work.

Ethical approval: Not required.

Data sharing: No additional data available.

Transparency: The lead authors affirm that the manuscript is an honest, accurate, and transparent account of the study being reported; that no important aspects of the study have been omitted; and that any discrepancies from the study as planned have been explained.

This is an Open Access article distributed in accordance with the Creative Commons Attribution Non Commercial (CC BY-NC 3.0) license, which permits others to distribute, remix, adapt, build upon this work non-commercially, and license their derivative works on different terms, provided the original work is properly cited and the use is non-commercial. See: http://creativecommons.org/licenses/ by-nc/3.0/.
DeFronzo RA, Abdul-Ghani M. Assessment and treatment of cardiovascular risk in prediabetes: impaired glucose tolerance and impaired fasting glucose. Am J Cardiol 2011;108(Suppl):3B-24B. doi:10.1016/j.amjcard.2011.03.013.

2 World Health Organization (WHO) Consultation. Definition and diagnosis of diabetes and intermediate hyperglycaemia.2006http:// www.who.int/diabetes/publications/Definition\%20and\%20 diagnosis\%20of\%20diabetes_new.pdf.

3 Expert Committee on the Diagnosis and Classification of Diabetes Mellitus. Report of the expert committee on the diagnosis and classification of diabetes mellitus. Diabetes Care 2003;26(Suppl 1):S5-20. doi:10.2337/diacare.26.2007.S5.

4 Rydén L, Grant PJ, Anker SD, et al. Authors/Task Force Members ESC Committee for Practice Guidelines (CPG) Document Reviewers. ESC Guidelines on diabetes, pre-diabetes, and cardiovascular diseases developed in collaboration with the EASD: the Task Force on diabetes, pre-diabetes, and cardiovascular diseases of the European Society of Cardiology (ESC) and developed in collaboration with the European Association for the Study of Diabetes (EASD). Eur Heart J 2013:34:3035-87. doi:10.1093/eurhearti/eht108.

5 Forouhi NG, Balkau B, Borch-Johnsen K, et al. EDEG. The threshold for diagnosing impaired fasting glucose: a position statement by the European Diabetes Epidemiology Group. Diabetologia 2006;49:822-7. doi:10.1007/s00125-006-0189-4.

6 Kim SH, Chunawala L, Linde R, Reaven GM. Comparison of the 1997 and 2003 American Diabetes Association classification of impaired fasting glucose: impact on prevalence of impaired fasting glucose, coronary heart disease risk factors, and coronary heart disease in a community-based medical practice. J Am Coll Cardiol 2006;48:293-7. doi:10.1016/j.jacc.2006.03.043.

De Caterina R, Madonna R. Impaired fasting plasma glucose and long-term cardiovascular risk: still a foggy relationship. Eur HeartJ 2010;31:1159-62. doi:10.1093/eurheartj/ehp589.

8 Liu J, Grundy SM, Wang W, et al. Ten-year risk of cardiovascula incidence related to diabetes, prediabetes, and the metabolic syndrome. Am Heart / 2007;153:552-8. doi:10.1016/j. ahj.2007.01.003.

9 Laukkanen JA, Mäkikallio TH, Ronkainen K, Karppi J, Kurl S. Impaired fasting plasma glucose and type 2 diabetes are related to the risk of out-of-hospital sudden cardiac death and all-cause mortality. Diabetes Care 2013:36:1166-71. doi:10.2337/dc12-0110.

10 Rijkelijkhuizen JM, Nijpels G, Heine RJ, Bouter LM, Stehouwer CD, Dekker JM. High risk of cardiovascular mortality in individuals with impaired fasting glucose is explained by conversion to diabetes: the Hoorn study. Diabetes Care 2007;30:332-6. doi:10.2337/ dc06-1238.

11 Levitzky YS, Pencina MJ, D’Agostino RB, et al. Impact of impaired fasting glucose on cardiovascular disease: the Framingham Heart Study. J Am Coll Cardiol 2008;51:264-70. doi:10.1016/j. jacc.2007.09.038.

12 Khang YH Cho SI, Kim HR. Risks for cardiovascular disease stroke, ischaemic heart disease, and diabetes mellitus associated with the metabolic syndrome using the new harmonised definition: findings from nationally representative longitudinal data from an Asian population. Atherosclerosis 2010;213:579-85. doi:10.1016/i. atherosclerosis.2010.09.009.

13 Xu T, Liu W, Cai X, et al. Risk of Coronary Heart Disease in Different Criterion of Impaired Fasting Glucose: A Meta-Analysis. Medicine (Baltimore) 2015;94:e1740. doi:10.1097/MD.0000000000001740.

14 Lee M, Saver JL, Hong KS, Song S, Chang KH, Ovbiagele B. Effect of pre-diabetes on future risk of stroke: meta-analysis. $B M$ J 2012:344:e3564. doi:10.1136/bmi.e3564

15 Ford ES, Zhao G, Li C. Pre-diabetes and the risk for cardiovascula disease: a systematic review of the evidence. J Am Coll Cardiol 2010:55:1310-7. doi:10.1016/i.jacc. 2009.10.060

16 Chatterton $\mathrm{H}$, Younger T, Fischer A, Khunti K. Programme Development Group. Risk identification and interventions to prevent type 2 diabetes in adults at high risk: summary of NICE guidance. $B M$ J 2012;345:e4624. doi:10.1136/bmj.e4624.

17 International Expert Committee. International Expert Committee report on the role of the $\mathrm{A} 1 \mathrm{C}$ assay in the diagnosis of diabetes. Diabetes Care 2009:32:1327-34. doi:10.2337/dc09-9033.

18 Stroup DF, Berlin JA, Morton SC, et al. Meta-analysis of observational studies in epidemiology: a proposal for reporting. Meta-analysis of Observational Studies in Epidemiology (MOOSE) group. JAMA 2000;283:2008-12. doi:10.1001/jama.283.15.2008.

19 Lorenzo C, Hartnett S, Hanley AJ, et al. Impaired fasting glucose and impaired glucose tolerance have distinct lipoprotein and apolipoprotein changes: the insulin resistance atherosclerosis study. J Clin Endocrinol Metab 2013;98:1622-30. doi:10.1210/ jc. 2012-3185.

20 Mostafa SA, Khunti K, Srinivasan BT, Webb D, Gray LI, Davies MJ. The potential impact and optimal cut-points of using glycated haemoglobin, $\mathrm{HbA1c}$, to detect people with impaired glucose regulation in a UK multi-ethnic cohort. Diabetes Res Clin Pract 2010;90:100-8. doi:10.1016/j.diabres.2010.06.008. 
21 Morris DH, Khunti K, Achana F, et al. Progression rates from HbA1C 6.0-6.4\% and other prediabetes definitions to type 2 diabetes: a meta-analysis. Diabetologia 2013:56:1489-93. doi:10.1007/ s00125-013-2902-4

22 Wells GA, Shea B, O'Connell D, et al. The Newcastle-Ottawa Scale (NOS) for assessing the quality of nonrandomised studies in meta-analyses. http://www.ohri.ca/programs/clinical_epidemiology/ oxford.asp.

23 Li M, Huang JT, Tan Y, Yang BP, Tang ZY. Shift work and risk of stroke: A meta-analysis. Int / Cardiol 2016;214:370-3. doi:10.1016/i. ijcard.2016.03.052.

24 Huang Y, Xu S, Hua J, et al. Association between job strain and risk of incident stroke: A meta-analysis. Neurology 2015;85:1648-54. doi:10.1212/WNL.0000000000002098.

25 Higgins JPT, Green S, eds. Cochrane Handbook for Systematic Reviews of Interventions Version 5.1.0 [updated March 2011]. The Cochrane Collaboration, 2011. http://handbook.cochrane.org.

26 Ziff OJ, Lane DA, Samra M, et al. Safety and efficacy of digoxin: systematic review and meta-analysis of observational and controlled trial data. BM/ 2015·351:h4451. doi:10.1136/bmi.h4451.

27 Brunström M, Carlberg B. Effect of antihypertensive treatment at different blood pressure levels in patients with diabetes mellitus: systematic review and meta-analyses. BMJ 2016;352:i717. doi:10.1136/bmj.i717.

28 Stengård JH, Tuomilehto J, Pekkanen J, et al. Diabetes mellitus, impaired glucose tolerance and mortality among elderly men: the Finnish cohorts of the Seven Countries Study. Diabetologia 1992;35:760-5

29 Barzilay Jl, Spiekerman CF, Wahl PW, et al. Cardiovascular disease in older adults with glucose disorders: comparison of American Diabetes Association criteria for diabetes mellitus with WHO criteria. Lancet 1999;354:622-5. doi:10.1016/S0140-6736(98)12030-5.

30 DECODE Study Group, the European Diabetes Epidemiology Group. Glucose tolerance and cardiovascular mortality: comparison of fasting and 2-hour diagnostic criteria. Arch Intern Med 2001;161:397-405. doi:10.1001/archinte.161.3.397.

31 Mazza A, Pessina AC, Pavei A, Scarpa R, Tikhonoff V, Casiglia E. Predictors of stroke mortality in elderly people from the general population. The CArdiovascular STudy in the ELderly. Eur J Epidemiol 2001;17:1097-104. doi:10.1023/A:1021216713504.

32 Saydah SH, Miret M, Sung J, Varas C, Gause D, Brancati FL. Postchallenge hyperglycemia and mortality in a national sample of U.S. adults. Diabetes Care 2001;24:1397-402. doi:10.2337/ diacare.24.8.1397.

33 Henry P, Thomas F, Benetos A, Guize L. Impaired fasting glucose, blood pressure and cardiovascular disease mortality. Hypertension 2002:40:458-63. doi:10.1161/01.HYP.0000032853.95690.26.

34 Rodriguez BL, Abbott RD, Fujimoto W, et al. American Diabetes Association World Health Organization. The American Diabetes Association and World Health Organization classifications for diabetes: their impact on diabetes prevalence and total and cardiovascular disease mortality in elderly Japanese-American men. Diabetes Care 2002;25:951-5. doi:10.2337/diacare.25.6.951.

35 Lu W, Resnick HE, Jain AK, et al. Effects of isolated post-challenge hyperglycemia on mortality in American Indians: the Strong Heart Study. Ann Epidemiol 2003;13:182-8. doi:10.1016/ S1047-2797(02)00274-0.

36 Hunt KJ, Resendez RG, Williams K, Haffner SM, Stern MP. San Antonio Heart Study. National Cholesterol Education Program versus World Health Organization metabolic syndrome in relation to all-cause and cardiovascular mortality in the San Antonio Heart Study. Circulation 2004:110:1251-7. doi:10.1161/01.CIR.0000140762.04598.F9.

37 Nakagami T. DECODA Study Group. Hyperglycaemia and mortality from all causes and from cardiovascular disease in five populations of Asian origin. Diabetologia 2004:47:385-94. doi:10.1007/ s00125-004-1334-6.

38 Nakanishi N, Takatorige T, Fukuda H, et al. Components of the metabolic syndrome as predictors of cardiovascular disease and type 2 diabetes in middle-aged Japanese men. Diabetes Res Clin Pract 2004;64:59-70. doi:10.1016/j.diabres.2003.10.001.

39 Tai ES, Goh SY, Lee JJ, et al. Lowering the criterion for impaired fasting glucose: impact on disease prevalence and associated risk of diabetes and ischemic heart disease. Diabetes Care 2004;27:1728-34. doi:10.2337/diacare.27.7.1728.

40 Hiltunen L. Ten-year mortality and glucose tolerance status in an elderly Finnish population. Diabetes Res Clin Pract 2005;69:81-7. doi:10.1016/j.diabres.2004.11.004.

41 McNeill AM, Rosamond WD, Girman C), et al. The metabolic syndrome and 11-year risk of incident cardiovascular disease in the atherosclerosis risk in communities study. Diabetes Care 2005;28:385-90. doi:10.2337/diacare.28.2.385

42 Wild SH, Smith FB, Lee AJ, Fowkes FG. Criteria for previously undiagnosed diabetes and risk of mortality: 15-year follow-up of the Edinburgh Artery Study cohort. Diabet Med 2005;22:490-6. doi:10.1111/j.1464-5491.2004.01433.x.
43 Kaarisalo MM, Räihä I, Arve S, Lehtonen A. Impaired glucose tolerance as a risk factor for stroke in a cohort of non-institutionalised people aged 70 years. Age Ageing 2006;35:592-6. doi:10.1093/ageing/ afl094.

44 McNeill AM, Katz R, Girman CJ, et al. Metabolic syndrome and cardiovascular disease in older people: The cardiovascular health study. J Am Geriatr Soc 2006;54:1317-24. doi:10.1111/j.1532-5415.2006.00862.x

45 Palmieri L, Donfrancesco C, Giampaoli S, et al. Favorable cardiovascular risk profile and 10-year coronary heart disease incidence in women and men: results from the Progetto CUORE. EurJ Cardiovasc Prev Rehabil 2006;13:562-70. doi:10.1097/01. hir.0000221866.27039.4b

46 Barr EL, Zimmet PZ, Welborn TA, et al. Risk of cardiovascular and all-cause mortality in individuals with diabetes mellitus, impaired fasting glucose, and impaired glucose tolerance: the Australian Diabetes, Obesity, and Lifestyle Study (AusDiab). Circulation 2007;116:151-7. doi:10.1161/CIRCULATIONAHA.106.685628

47 Nilsson PM, Engström G, Hedblad B. The metabolic syndrome and incidence of cardiovascular disease in non-diabetic subjects--a population-based study comparing three different definitions. Diabet Med 2007;24:464-72. doi:10.1111/j.1464-5491.2007.02142.x.

48 Pankow IS, Kwan DK, Duncan BB, et al. Cardiometabolic risk in impaired fasting glucose and impaired glucose tolerance: the Atherosclerosis Risk in Communities Study. Diabetes Care 2007;30:325-31. doi:10.2337/dc06-1457.

49 Wang J, Ruotsalainen S, Moilanen L, Lepistö P, Laakso M, Kuusisto J. The metabolic syndrome predicts cardiovascular mortality: a 13-year follow-up study in elderly non-diabetic Finns. Eur Heart / 2007;28:85764. doi:10.1093/eurhearti/ehl524.

50 Wang JJ, Li HB, Kinnunen L, et al. How well does the metabolic syndrome defined by five definitions predict incident diabetes and incident coronary heart disease in a Chinese population? Atherosclerosis 2007;192:161-8. doi:10.1016/j.atherosclerosis.2006. 04.027

51 Chien KL, Hsu HC, Su TC, Chen MF, Lee YT, Hu FB. Fasting and postchallenge hyperglycemia and risk of cardiovascular disease in Chinese: the Chin-Shan Community Cardiovascular Cohort study. Am Heart / 2008;156:996-1002. doi:10.1016/j.ahj.2008.06.019.

52 Jin M, Pan C, Tian H, et al Analysis of ten-year mortality in the male senile population with elevated fasting plasma glucose. Chinese I Endocrinol Metabol 2008;24:157-160. doi:10.3321/j. issn:1000-6699.2008.02.013

53 Kim NH, Pavkov ME, Looker HC, et al. Plasma glucose regulation and mortality in pima Indians. Diabetes Care 2008;31:488-92. doi:10.2337/dc07-1850.

54 Oizumi T, Daimon M, Jimbu Y, et al. Impaired glucose tolerance is a risk factor for stroke in a Japanese sample--the Funagata study. Metabolism 2008;57:333-8. doi:10.1016/j.metabol.2007.10.007.

55 Tsai SP, Wen CP, Chan HT, Chiang PH, Tsai MK, Cheng TY. The effects of pre-disease risk factors within metabolic syndrome on all-cause and cardiovascular disease mortality. Diabetes Res Clin Pract 2008;82:148-56. doi:10.1016/j.diabres.2008.07.016.

56 Wannamethee SG. The metabolic syndrome and cardiovascular risk in the British Regional Heart Study. Int) Obes (Lond) 2008;32(Suppl 2):S25-9. doi:10.1038/ijo.2008.32.

57 Hyvärinen M, Tuomilehto J, Mähönen M, et al. DECODE Study Group. Hyperglycemia and incidence of ischemic and hemorrhagic stroke-comparison between fasting and 2-hour glucose criteria. Stroke 2009;40:1633-7. doi:10.1161/STROKEAHA.108.539650.

58 Sung J, Song YM, Ebrahim S, Lawlor DA. Fasting blood glucose and the risk of stroke and myocardial infarction. Circulation 2009;119:812-9. doi:10.1161/CIRCULATIONAHA.108.776989.

59 Doi Y, Ninomiya T, Hata J, et al. Impact of glucose tolerance status on development of ischemic stroke and coronary heart disease in a general Japanese population: the Hisayama study. Stroke 2010;41:203-9. doi:10.1161/STROKEAHA.109.564708.

60 Kokubo Y, Okamura T, Watanabe M, et al. The combined impact of blood pressure category and glucose abnormality on the incidence of cardiovascular diseases in a Japanese urban cohort: the Suita Study. Hypertens Res 2010;33:1238-43. doi:10.1038/hr.2010.174.

61 Magliano DJ, Söderberg S, Zimmet PZ, et al. Mortality, all-cause and cardiovascular disease, over 15 years in multiethnic mauritius: impact of diabetes and intermediate forms of glucose tolerance. Diabetes Care 2010;33:1983-9. doi:10.2337/dc10-0312

62 Skriver MV, Borch-Johnsen K, Lauritzen T, Sandbaek A. HbA1c as predictor of all-cause mortality in individuals at high risk of diabetes with normal glucose tolerance, identified by screening: a follow-up study of the Anglo-Danish-Dutch Study of Intensive Treatment in People with Screen-Detected Diabetes in Primary Care (ADDITION), Denmark. Diabetologia 2010;53:2328-33. doi:10.1007/ s00125-010-1867-9.

63 Sui X, Lavie CJ, Hooker SP, et al. A prospective study of fasting plasma glucose and risk of stroke in asymptomatic men. Mayo Clin Proc 2011:86:1042-9 doi:10.4065/mcp.2011.0267. 
64 Yeboah J, Bertoni AG, Herrington DM, Post WS, Burke GL. Impaired fasting glucose and the risk of incident diabetes mellitus and cardiovascular events in an adult population: MESA (Multi-Ethnic Study of Atherosclerosis). J Am Coll Cardiol 2011;58:140-6. doi:10.1016/j.jacc.2011.03.025.

65 Ma SH, Park BY, Yang Jl, et al. Interaction of body mass index and diabetes as modifiers of cardiovascular mortality in a cohort study. J Prev Med Public Health 2012;45:394-401. doi:10.3961/jpmph.2012.45.6.394.

66 Deedwania P, Patel K, Fonarow GC, et al. Prediabetes is not an independent risk factor for incident heart failure, other cardiovascular events or mortality in older adults: findings from a population-based cohort study. Int J Cardiol 2013;168:3616-22. doi:10.1016/j. ijcard.2013.05.038.

$67 \mathrm{Kim} \mathrm{HK}$, Kim CH, Kim EH, et al. Impaired fasting glucose and risk of cardiovascular disease in Korean men and women: the Korean Heart Study. Diabetes Care 2013:36:328-35. doi:10.2337/dc12-0587.

68 Onat A, Can G, Çiçek G, Ayhan E, Doğan Y, Kaya H. Fasting, non-fasting glucose and $\mathrm{HDL}$ dysfunction in risk of pre-diabetes, diabetes, and coronary disease in non-diabetic adults. Acta Diabetol 2013;50:51928. doi:10.1007/s00592-011-0313-x.

69 Schöttker B, Müller H, Rothenbacher D, Brenner H. Fasting plasma glucose and $\mathrm{HbA} 1 \mathrm{c}$ in cardiovascular risk prediction: a sex-specific comparison in individuals without diabetes mellitus. Diabetologia 2013:56:92-100. doi:10.1007/s00125-012-2707-x

70 Selvin E, Lazo M, Chen Y, et al. Diabetes mellitus, prediabetes, and incidence of subclinical myocardial damage. Circulation 2014:130:1374-82. doi:10.1161/CIRCULATIONAHA.114.010815.

71 Eastwood SV, Tillin T, Sattar N, Forouhi NG, Hughes AD, Chaturvedi N. Associations Between Prediabetes, by Three Different Diagnostic Criteria, and Incident CVD Differ in South Asians and Europeans. Diabetes Care 2015;38:2325-32. doi:10.2337/dc15-1078.

72 Gordon-Dseagu VL, Mindell JS, Steptoe A, et al. Impaired glucose metabolism among those with and without diagnosed diabetes and mortality: a cohort study using Health Survey for England data. PLOS One 2015;10:e0119882. doi:10.1371/journal.pone.0119882.

73 Paprott R, Schaffrath Rosario A, Busch MA, et al. Association between hemoglobin A1c and all-cause mortality: results of the mortality follow-up of the German National Health Interview and Examination Survey 1998. Diabetes Care 2015;38:249-56. doi:10.2337/dc14-1787.

74 Samaras K, Crawford J, Lutgers HL, et al. Metabolic Burden and Disease and Mortality Risk Associated with Impaired Fasting Glucose in Elderly Adults. J Am Geriatr Soc 2015;63:1435-42. doi:10.1111/jgs.13482.

$75 \mathrm{Kim} \mathrm{HK}$, Lee JB, Kim SH, et al. Association of prediabetes, defined by fasting glucose, $\mathrm{HbA1}$ c only, or combined criteria, with the risk of cardiovascular disease in Koreans. J Diabetes 2016;8:657-66 doi:10.1111/1753-0407.12343.

76 Huang Y, Cai X, Chen P, et al. Associations of prediabetes with all-cause and cardiovascular mortality: a meta-analysis. Ann Med 2014;46:684-92. doi:10.3109/07853890.2014.955051.
77 Hu G. DECODE Study Group. Gender difference in all-cause and cardiovascular mortality related to hyperglycaemia and newlydiagnosed diabetes. Diabetologia 2003;46:608-17. doi:10.1007/ s00125-003-1096-6.

78 Bullard KM, Saydah SH, Imperatore G, et al. Secular changes in U.S Prediabetes prevalence defined by hemoglobin A1 $\mathrm{c}$ and fasting plasma glucose: National Health and Nutrition Examination Surveys, 1999-2010. Diabetes Care 2013;36:2286-93. doi:10.2337/ dc12-2563.

79 Xu Y, Wang L, He J, et al. 2010 China Noncommunicable Disease Surveillance Group. Prevalence and control of diabetes in Chinese adults. JAMA 2013;310:948-59. doi:10.1001/jama.2013.168118.

80 Nathan DM, Davidson MB, DeFronzo RA, et al. American Diabetes Association. Impaired fasting glucose and impaired glucose tolerance: implications for care. Diabetes Care 2007;30:753-9. doi:10.2337/dc07-9920.

81 Yoon U, Kwok LL, Magkidis A. Efficacy of lifestyle interventions in reducing diabetes incidence in patients with impaired glucose tolerance: a systematic review of randomized controlled trials. Metabolism 2013:62:303-14. doi:10.1016/j.metabol.2012.07.009.

82 Yates T, Haffner SM, Schulte PJ, et al. Association between change in daily ambulatory activity and cardiovascular events in people with impaired glucose tolerance (NAVIGATOR trial): a cohort analysis. Lancet 2014;383:1059-66. doi:10.1016/S0140-6736(13)62061-9.

83 Li G, Zhang P, Wang J, et al. Cardiovascular mortality, all-cause mortality, and diabetes incidence after lifestyle intervention for people with impaired glucose tolerance in the Da Qing Diabetes Prevention Study: a 23-year follow-up study. Lancet Diabetes Endocrinol 2014;2:474-80. doi:10.1016/S2213-8587(14)70057-9.

84 Buysschaert M, Medina JL, Bergman M, Shah A, Lonier J. Prediabetes and associated disorders. Endocrine 2015;48:371-93. doi:10.1007/ s12020-014-0436-2

85 Ferrannini E. Definition of intervention points in prediabetes. Lancet Diabetes Endocrinol 2014:2:667-75. doi:10.1016/ S2213-8587(13)70175-X

86 Harding JL, Soderberg S, Shaw JE, et al. All-cause cancer mortality over 15 years in multi-ethnic Mauritius: the impact of diabetes and intermediate forms of glucose tolerance. Int J Cancer 2012;131:238593. doi:10.1002/ijc. 27503.

Appendix 1: Literature search strategy for all the databases

Appendix 2: Supplementary tables A-F Appendix 3: Supplementary figures A-D (funnel plots for detection for publication bias)

Appendix 4: Supplementary forest plots A-B 